\title{
MOBILIDADE E DINÂMICA NO ESPAÇO RURAL E URBANO EM SÃO CRISTÓVÃO NO ESTADO DE SERGIPE/BRASIL
}

\author{
Carlos Alberto Vasconcelos ${ }^{1}$ \\ Otávio César Juliano de Souza ${ }^{2}$
}

\begin{abstract}
Resumo
O presente trabalho apresenta e discute as modificações ocorridas no espaço geográfico do município de São Cristóvão/SE, nas décadas de 1980, 1990 e 2000, no tocante à mobilidade e dinâmica do espaço rural e urbano. Utilizaram-se dados cadastrais de órgãos oficiais, como o IBGE, INCRA, DEAGRO e Prefeitura Municipal, pesquisa de campo, baseando-se em autores que tratam da temática, a exemplo de Corrêa (1995), Oliveira (1997) e Souza (2005), para a compreensão e elucidação dos acontecimentos. Observa-se um processo difuso de urbanização não centrado na sede, e sim seguindo da periferia em direção ao campus da Universidade Federal de Sergipe, próximo à área limítrofe com Aracaju. O rural e o urbano passaram por um processo de especulação pelo poder estatal.
\end{abstract}

Palavras-chave: Município de São Cristóvão; Mobilidade Urbana e Rural; Espaço.

\section{MOBILITY AND DYNAMICS IN RURAL AND URBAN IN SAINT KITTS IN STATE SERGIPE/BRAZIL}

\begin{abstract}
This paper presents and discusses the changes in the geographical area of the municipality of Saint Kitts/SE, in the decades of 1980, 1990 and 2000 regarding the mobility and dynamics of rural and urban areas. Was used registration data to official bodies, such as IBGE, INCRA, DEAGRO and City Hall, field research, based on authors who treat the theme, like Correa (1995), Oliveira (1997) and Souza (2005) for the understanding and elucidation of events. Was observed a diffuse process of urbanization not focused on centered on the seat, and yes it following the periphery toward the campus of the Federal University of Sergipe, in the border area next with Aracaju; the rural and urban they passed through a process of speculation the state power.
\end{abstract}

Keywords: County of Saint Kitts; Mobility urban and rural; Space.

\footnotetext{
${ }^{1}$ Doutor em Geografia pela Universidade Federal de Sergipe (UFS) e Pós-Doutor pela Universidade Federal de Pernambuco (UFPE). Professor do Departamento de Educação do campus Prof. Alberto Carvalho da Universidade Federal de Sergipe (UFS). Email: geopedagogia@yahoo.com.br ${ }^{2}$ Graduado e Mestre em Geografia. Professor da Educação Básica na Rede Estadual de Ensino de Pernambuco.
Email: jullianosouza9@gmail.com
}

Sociedade e Território - Natal. Vol. 28, N. 1, p. 88-107. Jan./Jun. de 2016 


\section{MOBILITÉ ET DYNAMIQUE EN MILIEU RURAL ET URBAIN DANS L'ETAT SONT CRISTOVÃO SERGIPE/BRESIL}

\section{Résumé}

Cet article présente et discute les changements dans la zone géographique de la municipalité de São Cristóvão / SE, dans les années 1980, 1990 et 2000 en ce qui concerne la mobilité et la dynamique des zones rurales et urbaines. Nous avons utilisé les données d'enregistrement à des organismes officiels, tels que IBGE, INCRA, DEAGRO et la Préfecture municipale, recherches sur le terrain, basé sur les auteurs qui traitent du sujet, exemple, Corrêa (1995), Oliveira (1997) e Souza (2005), pour la compréhension et la clarification des événements. On observe un processus d'urbanisation diffuse pas centrée au siège, mais la suite de la périphérie vers le campus de Universidade Federal de Sergipe, près de la zone frontalière avec le Aracaju; rural et urbain est passé par un processus de spéculation pour le pouvoir d'Etat.

Mots-clés: municipalité de São Cristóvão; la mobilité urbaine; la zone rurale.

\section{INTRODUZINDO A QUESTÃO}

Dinâmicas e movimentos no espaço geográfico são focos centrais de abordagens recentes, que procuram caracterizar a evolução do urbano e do rural, bem como das relações que emergem de ambos. O processo de urbanização, que se intensificou a partir da Primeira Revolução Industrial, trouxe grandes transformações para as cidades de todo o mundo. No Brasil, essas modificações começaram a ser mais enfáticas em meados do século XX, alterando a estrutura de núcleos urbanos, provocada pelas modificações intensas no campo, que aumentaria a demanda por moradias, estimulando estratégias clientelistas e de financiamentos da habitação, a partir da intervenção do Estado.

Nesta perspectiva a dinâmica espacial do município de São Cristóvão está atrelada, sobretudo, às intervenções efetivadas pelo poder público local com a finalidade de redimensionar o espaço urbano e o rural, movido pela necessidade da introdução dos programas do Estado. Daí a preocupação em elucidar o uso e a ocupação do solo do município, no que diz respeito ao que está exposto nos documentos oficiais.

Desta feita, é notável em estudos sobre a urbanização do rural, a exemplo do de Corrêa (1995), a crescente participação do poder público, a progressiva concentração geográfica das atividades econômicas, a criação de centros secundários nos limites urbanos, o crescimento da atuação das empresas construtoras e imobiliárias e a consequente expansão espacial das periferias. Todos esses fatores explicam a disposição espacial dos aglomerados urbanos 
atuais, pois, na medida em que o espaço urbano não comporta as modificações advindas por esses fatores, inicia-se a ocupação de novas áreas, mesmo fora de seus limites territoriais.

A esse respeito Oliveira (1997) argumentará que políticas de desenvolvimento urbano se vinculam à centralização e controle, mas que a investigação deve se dar também sobre o grupo social. Isso permite entender que a sociedade é dinâmica e se movimenta em prol da resolução de suas necessidades.

Esses fatores manifestam-se por intermédio das forças do capital, da pressão populacional pela necessidade de espaços para implantação das habitações e pela atuação do poder público. A intervenção do poder público na esfera nacional se dá através da execução de obras de infraestrutura, como instalação de rede elétrica e de vias de comunicação e, também, pela nova política habitacional do Banco Nacional de Habitação (BNH), o que provoca forte impulso na indústria da construção civil.

A partir daí surgem os agentes promotores dessa organização espacial, entre os quais estão o poder político antes citado, as imobiliárias e/ou proprietários ou não da terra e agentes financeiros da habitação, como o $\mathrm{BNH}$, cada um com sua função, com o seu objetivo e realizando suas ações. O poder público estimula, através da concessão do espaço, novas formas de crescimento econômico, sobretudo com o incentivo a financiamentos e com a arrecadação de impostos. Na esfera da economia, aguarda-se um incremento que vise a atrair a instalação de indústrias e de empresas, cujo respaldo será a absorção da mão de obra, o que gerará renda in loco.

O Estado, por sua vez, atua como agente modelador do solo urbano, criando mecanismos para a sua própria atuação e para a de outros agentes modeladores dos espaços que agem com os mesmos propósitos, direta ou indiretamente. Ele possui grande poder de organizar as decisões, como também tem poderes para modificar o uso do solo, tornando-se necessário o seu aval para os projetos de renovação urbana (CORRÊA, 1995).

Desta forma, observa-se que a expansão física da cidade de São Cristóvão ocorre em virtude de grandes empreendimentos, como o da construção civil, com a inserção de novos espaços produzidos, como o do bairro Jardim Rosa Elze, em detrimento do espaço rural que tem o uso do solo transformado pelas políticas municipais, denunciando processo de urbanização no território municipal. Tal procedimento se legitima pelo papel exercido pelo Estado, agente importante no que toca a essas estratégias, conforme já discutiu Corrêa (1995), 
apontando que ele age de modo direto e indireto, facilitando a acumulação capitalista, no contexto de produção imobiliária.

Assim, o Estado cria leis e normas que favorecem o uso do solo para fins de urbanização. Em 1989, a Constituição Estadual de Sergipe alterou o limite do município de São Cristóvão com o município de Aracaju, tendo em vista o Plano de Desenvolvimento Urbano e Regional da Grande Aracaju.

A partir da Lei Complementar n ${ }^{\circ}$ 25, de 29 de dezembro de 1995, foi criada a Região Metropolitana de Aracaju (RMA). O artigo $2^{\circ}$ dessa lei aponta que a RMA será constituída pelo agrupamento dos municípios de Aracaju, São Cristóvão, Nossa Senhora do Socorro e Barra dos Coqueiros. Assim, o Estado passa a definir ações no que tange à infraestrutura da área, favorecendo a implementação de uma política voltada às questões econômicas, sobretudo.

Ao retomar o pensamento de Oliveira (1997), observa-se que, ao buscar a resolução dos "problemas" evidenciados na cidade, a ingerência do Estado torna-se, várias vezes, legitimada como uma prática exclusiva por grande parte dos moradores. Nesse sentido, observa-se o município de São Cristóvão, por legislação, definindo "zona urbana" e “expansão urbana”, no território (PREFEITURA Municipal de São Cristóvão, 1984). Deste modo, mais de $70 \%$ de área está voltada ao crescimento urbano e menos de 30\% direcionado ao espaço rural, independentemente das práticas espaciais que aí são estabelecidas.

O espaço se torna urbano ou rural de acordo com as interferências do poder municipal, uma vez que as leis são elaboradas por ele, o qual pode estar atrelado inclusive a interesses particulares, principalmente na perspectiva de novos investimentos e de arrecadações de impostos, que são diferentes em áreas rurais e urbanas. Ressalta-se a Lei complementar n. 32, de 24 de dezembro de 2013, que dispõe sobre redução de alíquotas para cálculo do Imposto Predial e Territorial Urbano - IPTU; institui Planta Genérica de Valores Imobiliários da Área Urbana para fins de cálculo do IPTU e do Imposto de Transmissão de Bens Imóveis Intervivos - ITBI; e dá providências correlatas. Essa lei complementa, estabelece e, de certa forma, valoriza o espaço urbano, em detrimento do rural, aguçando maior valor e alíquotas aos espaços, para fins de arrecadações e valorização.

$\mathrm{Na}$ verdade, as delimitações entre o rural e o urbano no município de São Cristóvão tinham como objetivo a arrecadação de recursos federais pela Prefeitura, a fim de promover a produção local de forma racional e sustentável. 
Deste modo, o presente texto objetiva discutir as modificações ocorridas no espaço geográfico de São Cristóvão, o qual faz parte da Grande Aracaju, nas décadas de 1980, 1990 e 2000, no tocante à mobilidade e dinâmica do espaço rural e urbano. Para tal, foram utilizados dados cadastrais de órgão oficiais, a exemplo do Instituto Brasileiro de Geografia e Estatística (IBGE), Instituto Nacional de Colonização e Reforma Agrária (INCRA), Departamento de Desenvolvimento Agrário de Sergipe (DEAGRO) e Prefeitura de São Cristóvão, além de leis e decretos municipais, bem como de pesquisa de campo, baseando-se em autores que tratam da temática, a exemplo de Souza (2005) e Côrrea (1993).

\section{DELINEANDO O ESPAÇO URBANO E RURAL DE SÃO CRISTÓVÃO}

É notável encontrar-se área definida por lei municipal como de expansão urbana, muito embora se percebam na paisagem elementos indicativos de espaço rural, o que conduz à reflexão de que, mesmo a Lei ${ }^{0} 21$ de 2002 tendo reduzido a área urbana que consta na Lei $\mathrm{n}^{\mathrm{o}} 16$ de 1984, ainda se encontram atividades rurais em espaços urbanos.

Para melhor ilustrar e esclarecer o porquê de a lei $\mathrm{n}^{\circ} 16$ de 1984 ter ampliado a área urbana, em entrevista, um ex-prefeito de São Cristóvão, Sr. Horácio Souza Lima, acrescenta que a Lei $n^{\circ} 21$ de 2002, que reduziu a área urbana, foi elaborada em função da necessidade do financiamento do crédito rural do Banco do Nordeste do Brasil (BNB) para o setor rural. Ele considerou que o prefeito da época sancionou a referida lei como uma exigência do BNB.

A ampliação do espaço físico dos diversos núcleos urbanos sãocristovenses é um fato que indica um movimento ininterrupto do crescimento do município. A paisagem nesses núcleos ampliados exprime, contudo, características nitidamente rurais, embora o conteúdo do supracitado documento definisse todos os espaços como eminentemente urbanos.

Há uma nítida compartimentação do espaço em termos de qualidade ambiental e serviços básicos (abastecimento de água, instalação sanitária, destino do lixo), dos quais só as áreas mais próximas aos núcleos urbanos mostram-se mais servidas, pois se trata de uma periferia planejada. Os novos loteamentos e diversos condomínios apresentam esses elementos, evidenciando a estratificação sócio-ambiental existente no município por conta da forma de ocupação do espaço. 
Nossa pesquisa demonstrou que a aplicação da lei de 1984 ampliou o perímetro urbano, envolvendo extensas áreas até então rurais que obtiveram, previamente, o status de áreas urbanas.

As atividades exercidas no espaço não mudam necessariamente de imediato quando o uso do solo para urbano é estabelecido, porque o rebatimento é decorrente dos investimentos de outras políticas do Estado. Assim, este intervém, pelas políticas públicas, determinando sua produção. Cite-se, a exemplo, a política do BNB que, através da extinta COHAB (Companhia Habitacional), impôs condições para a construção de conjuntos habitacionais somente em espaços definidos como urbanos.

A instituição de novas políticas públicas direcionadas ao rural pelo Estado levou o poder público local, por meio da Lei $\mathrm{n}^{\circ} 21$, de 18 de dezembro de 2002, a revogar a lei anterior, alterando, com isso, mais uma vez a delimitação do urbano/rural, como forma de garantir recursos à municipalidade. Essa nova lei retrata melhor a realidade e está respaldada nos critérios do IBGE a partir dos censos de 1991 e 2000. Assim, com a lei de 2002, constatase uma reorganização espacial que reduz a área urbana em prol da área rural. Porém, as áreas atualmente definidas como áreas de expansão urbana, por essa lei, ainda apresentam características nitidamente rurais, suscitando questionamentos sobre o perímetro definido e o processo de delimitação da zona urbana e rural.

Conveniente se faz ressaltar que o trabalho de campo originário deste texto, em alguns casos, foi realizado no espaço que atualmente é considerado rural, denominado pelo IBGE como aglomerados urbanos com características de rurais (setores analisados) e onde os entrevistados, durante a pesquisa de campo, em sua maioria, não concebiam sua inserção na área urbana em função da atividade que desenvolviam, basicamente rural.

Ao longo das últimas décadas, observa-se que o território municipal de São Cristóvão incorporou bastante infraestrutura, porque os elementos que caracterizam uma área urbana são incorporados e vêm crescendo nos setores censitários urbanos com características de rural, embora algumas dessas áreas mantenham deficiência de serviços, o que implica um reflexo da política efetivada pelo poder público local, conforme investigação mais recente.

A urbanização mais recente do território municipal de São Cristóvão ocorre provocando hiatos espaciais, em relação à sede municipal, pela produção de conjuntos habitacionais na década de 1980 atraídos pela infraestrutura promovida pela instalação da Universidade Federal de Sergipe, estendendo-se, embora precariamente, para os setores- 
urbanos, ainda com características rurais. Ela sugere, assim, estar vinculada à expansão da Grande Aracaju, não desvencilhada da dinâmica da economia estadual com interesses de financiamentos de programas do Governo Federal.

A cidade de Aracaju, capital do estado de Sergipe, exerce uma forte influência sobre os munícipes sãocristovenses e permite que se constatem migrações pendulares em busca de serviços e atividades comerciais que, indubitavelmente, são bem mais abrangentes ali. Há esse fluxo de munícipes de São Cristóvão para Aracaju, como também deve-se registrar um movimento inverso, pelo qual moradores da capital se dirigem às localidades rurais de São Cristovão, a fim de desfrutarem de um ambiente bucólico, calmo e sossegado. Este fenômeno provoca modificações estruturais compondo áreas de grupos sociais diferenciados diretamente relacionados à época de ocupação, planejamento urbano e políticas habitacionais dos governos estadual e federal, investimento público aplicado, influência das imobiliárias e construtoras e, principalmente, ao nível sócio-econômico da população residente.

Desse modo, torna-se claro que a explicação para o surgimento de problemas como baixa renda, desemprego, condições precárias de moradia, migrações, marginalização, entre outros, não se subsome apenas a questões relacionadas ao contexto demográfico ou espacial, visto que tais fenômenos são resultantes de processos políticos, econômicos e sociais altamente complexos.

Os estímulos dados pelos programas federais incentivaram o poder público local a interferir no espaço através da delimitação do perímetro urbano, indicando que provavelmente outras ingerências poderão ser realizadas, caso seja necessário moldar o território aos interesses públicos, como ocorreu em 1984 e em 2002.

O espaço em foco, apesar das diferentes formas de organização, apresenta-se com baixo nível de mobilização ou de transformação pelo capital. A diferenciação espacial reflete uma estratificação social, sobretudo no campo, onde há uma minoria privilegiada pelo monopólio do principal meio de produção, a terra. $\mathrm{O}$ vasto contingente é representado pelas populações rurais desprovidas de acesso a uma infraestrutura econômica, que, embora contribua com seu trabalho para o desenvolvimento capitalista, permanece à margem de seus benefícios. 


\section{AS TRANSFORMAÇÕES DO ESPAÇO RURAL/URBANO EM SÃO CRISTÓVÃO}

A reflexão sobre as transformações que vêm ocorrendo em São Cristóvão conduz a questionamentos sobre como tem sido concebido o rural e o urbano no município, do ponto de vista de seus planejadores. Assim, a análise dos resultados alcançados pela pesquisa é desenvolvida através das informações obtidas de acordo com os setores censitários. Tais informações levam a uma compreensão dos espaços urbanos e rurais em função dos processos recentes de transformações socioeconômicas.

A tabela 01 mostra os índices da população urbana e rural e permite constatar que, em 1970 e 1980, a população rural era superior à urbana. Já em 1991 e 2000, verifica-se um aumento de $97,21 \%$ e 97,63\%, respectivamente, na população urbana. A pesquisa documental, portanto, permite evidenciar que este fato está atrelado à Lei no 16 de 1984, que ampliou a zona urbana e de expansão urbana no território político-administrativo de São Cristóvão, envolvendo um novo incremento populacional urbano.

Tabela 01: Distribuição da população por situação do domicílio no município de São Cristóvão/SE, 1970, 1980, 1991, 2000 e 2010.

\begin{tabular}{|c|c|c|c|c|c|}
\hline \multirow[t]{2}{*}{ ANO } & \multirow[t]{2}{*}{ TOTAL } & \multicolumn{2}{|c|}{ URBANA } & \multicolumn{2}{|c|}{ RURAL } \\
\hline & & Total & $\%$ & Total & $\%$ \\
\hline 1970 & 20.409 & 10.152 & 49,74 & 10.257 & 50,25 \\
\hline 1980 & 24.134 & 11.703 & 48,49 & 12.431 & 51,51 \\
\hline 1991 & 47.558 & 46.233 & 97,21 & 1.325 & 2,79 \\
\hline 2000 & 64.647 & 63.116 & 97,63 & 1.531 & 2,37 \\
\hline
\end{tabular}

Fonte: IBGE. Censos Demográficos, 1970, 1980, 1991, 2000 e 2010.

Ao refletir acerca da dinâmica socioeconômica do espaço em que está inserido, o município de São Cristóvão vem ganhando contingente populacional de forma mais acentuada, a partir da década de 1980, como mostra o censo de 1991, e continua com os decênios seguintes, com a revelação dos dados dos censos de 2000 e 2010, registrando índices maiores de crescimento populacional. Esse incremento foi verificado graças à taxa geométrica de crescimento anual.

Quanto à questão do crescimento urbano, acredita-se que um dos fatores de contribuição à ampliação da taxa de urbanização, verificada em 1991 e 2000, está atrelado à aprovação da Lei $n^{\circ}$ 16/1984, que incluiu uma grande porção da antiga população rural no novo perímetro urbano. Por outro lado, pode-se destacar que este alto crescimento verificado 
no período relaciona-se à construção de conjuntos habitacionais e de loteamentos, o que estimulou um incremento populacional urbano proveniente de outros municípios sergipanos. Registra-se, pelo Censo Demográfico de 1991, que o quantitativo de pessoas não naturais do município correspondia a 24.380 habitantes, sendo que 24.162 destes eram residentes na zona urbana e 218 residentes na zona rural.

Em relação à ocupação da população, de modo geral, percebe-se que ela desenvolve atividades eminentemente secundárias e terciárias, segundo critério econômico. Observa-se que a distribuição da população, por setor de atividade, concentra-se no setor terciário, cuja expressividade se deve a sua capacidade de absorver mão de obra. Por sua vez, há um declínio na ocupação do setor primário, no período de 1980 a 2000.

É possível constatar uma mudança na participação da população por setores de economia quando se comparam a distribuição quase equitativa dos três setores, em 1980, o crescimento vertiginoso em 1991 do setor terciário $(64,50 \%)$ e a manutenção desse quadro em 2000. Evidencia-se, desta forma, o quanto o processo de incorporação do município à Grande Aracaju e os equipamentos e infraestrutura decorrentes exerceram influência sobre as mudanças já configuradas, provocando uma redução nas atividades ditas primárias, quando os produtos da lavoura e da pecuária já não se destacavam devido a uma série de fatores, entre eles, a inadequação do solo.

A partir da contextualização explícita e dos diversos fenômenos observados no município de São Cristóvão, as questões relacionadas ao rural e ao urbano devem ser também analisadas pelo prisma de outras ciências e não apenas da discussão geográfica, estimulando e contribuindo para a análise dos fatores que ocasionaram as modificações socioespaciais, especificamente no período de 1980 a 2004.

\section{A DINÂMICA URBANA: O EXEMPLO DO BAIRRO JARDIM ROZA ELZE E AS POLÍTICAS DE URBANIZAÇÃO}

O bairro Jardim Rosa Elze dista $4 \mathrm{~km}$ de Aracaju e $14 \mathrm{~km}$ de São Cristóvão. Juntamente com as novas aglomerações que surgiram no seu entorno, esse bairro tem uma dinâmica urbana completamente diferenciada da sede municipal. Trata-se de uma região inserida em perímetro urbano, porém completamente destacada da área urbana da sede, e muito mais ligada à periferia de Aracaju, sendo que, segundo Guimarães (2004), a relação econômico-social entre as cidades é positiva, gerando questões de ordem comum. 
As aglomerações que surgiram no seu entorno deram origem ao GRE (Grande Rosa Elze), compondo onze núcleos que, juntos, formam a porção mais habitada do município de São Cristóvão. Com uma população em torno de 50.000 habitantes, está localizada no extremo norte do município, fazendo limite com Aracaju. Sua composição compreende os seguintes núcleos: o Jardim Rosa Elze, Jardim Rosa Maria, Jardim Universitário, Conj. Brigadeiro Eduardo Gomes, Loteamento Tijuquinha, Conj. Lafaiete Coutinho, Conj. Madre Paulina, Conj. Luís Alves, Conj. Maria do Carmo III, Lot. Rosa do Oeste e o Conj. Vilas de São Cristóvão. Dentre eles, o Rosa Elze e o Eduardo Gomes, apesar de surgirem posteriormente ao Rosa Maria, constituem-se núcleos habitacionais de maior relevância para o conjunto dessa área do município. Tal relevância é justificada por Lima (2006) ao entender que os dois primeiros núcleos habitacionais citados foram frutos de políticas públicas de ordenação do uso e ocupação do solo e, portanto, dotados de infraestrutura, enquanto que o mesmo não ocorre com o Rosa Maria. Para Rodrigues (2005), o Conjunto Brigadeiro Eduardo Gomes é dotado de serviços mais especializados, indicando a formação de centralidades, pois os habitantes dos conjuntos e loteamentos do seu entorno usufruem, em grande parte, dos serviços por ele oferecidos.

Percebe-se que na constituição dessa área residencial há, porém, no entorno, resquícios de atividade rural que, gradativamente, vem dando lugar aos lotes residenciais. Quando surgiu o primeiro loteamento - o Rosa Maria -, dificilmente se imaginaria a existência de um núcleo habitacional na área, pois, conforme depoimento de um morador entrevistado por Lima (2006), o acesso a Aracaju era difícil, sendo realizado por uma estrada de terra que impossibilitava, em períodos chuvosos, o tráfego de veículos. Por conseguinte, a travessia do Rio Poxim, que faz limite entre os municípios de Aracaju e São Cristóvão, era feita por uma ponte de madeira, que dificultava ainda mais o acesso à capital.

Contudo, na década de 1970, a Universidade Federal de Sergipe (UFS) adquiriu de uma construtora "os terrenos" da Fazenda Santa Cruz para a instalação do Campus Universitário, no município de São Cristóvão, numa área contígua a Aracaju. Desde então, a área tornou-se objeto de especulação imobiliária, desencadeando a intensificação de dois loteamentos periféricos, o Jardim Rosa Elze e o Jardim Rosa Maria. De acordo com França (1999), a área adquirida pela UFS compreendia 152 hectares e, como objetivo do projeto, além da construção do Campus Universitário, estava a construção de residências para os docentes e funcionários. 
De acordo com o autor mencionado anteriormente, a escolha da área para construção do Campus Universitário obedecia a uma proposta de metropolização, então vigente, a qual consistia na construção de conjuntos habitacionais para diminuir o déficit habitacional de Aracaju e, concomitantemente, reduzir a concentração de pessoas na capital, acentuando ainda mais, aí, a especulação imobiliária.

Discutindo a questão Souza (2005, p. 97), acrescenta:

O avanço habitacional direcionado pelo município de Aracaju sobre as terras circunvizinhas do município de São Cristóvão fazia parte do processo de pré metropolização da cidade de Aracaju, onde se observa com bastante clareza ser esta uma estratégia para valorização do solo da capital.

Ainda segundo o autor mencionado, com o processo de pré-metropolização houve uma forte valorização da terra local e, paralelamente, a valorização do solo aracajuano, pois o processo de parcelamento da zona rural de São Cristóvão para fins urbanos proporcionou o aparecimento de loteamentos e conjuntos habitacionais nas áreas limítrofes com a capital. Então, "iniciava-se uma mudança no uso do solo: da ocupação rural com sítios, onde eram frequentes os pomares [...], surge uma ocupação que se acentuava à proporção que se intensificavam as obras de implantação do Campus Universitário" (FRANÇA, 1999, p. 92).

Com a mudança da Universidade Federal de Sergipe para o Campus, em 1981, foi dado novo dinamismo para os loteamentos adjacentes, intensificando a ocupação do Rosa Elze. Tal mudança permitiu melhores condições de acesso e transporte, acelerando a ocupação dos loteamentos vizinhos e a proliferação de novos empreendimentos, cuja iniciativa perfazia um total de 129 projetos com mais de 45.000 lotes implantados e/ou aprovados pela Prefeitura Municipal de São Cristóvão até o ano de 2004 (SOUZA, 2005).

A década de 1980 foi o marco das transformações urbanas na região, uma vez que a UFS iniciou as suas atividades e a COHAB-SE adquiriu terras nas proximidades do bairro para a construção de um conjunto habitacional. França (1999) relata que foi adquirido um imóvel rural denominado "Sítio Cheiroso", cuja extensão totalizava 1.015.613,50 m2, localizado entre a Rodovia João Bebe Água (ao sul) e o Rio Poxim (ao norte), distando 4 km do Campus Universitário e a $6 \mathrm{~km}$ da malha urbana de Aracaju. Após a execução do projeto (1984) o conjunto recebeu o nome de Brigadeiro Eduardo Gomes, já citado anteriormente, contando com 3.109 unidades habitacionais construídas, das quais 1.030 com um quarto, 809 
com dois quartos, 527 com três quartos e 743 com quatro quartos, que acentuou ainda mais o processo de urbanização da região.

Nesse cenário, “a política habitacional ${ }^{3}[\ldots]$ emerge como modelo empresarial, com objetivo de atacar problemas sociais, resolvendo a questão da moradia" (SOUZA, 2004, p.96). Por conseguinte, a criação de órgãos, como o BNH, as Cooperativas de Habitação (COHABs) e a criação de mecanismos jurídicos e financeiros, como o Fundo de Garantia por Tempo de Serviço (FGTS), visavam viabilizar a acumulação capitalista via produção de habitações, cujo acesso foi ampliado (CORRÊA, 1993).

A atuação da política habitacional em São Cristóvão por meio da COHAB marca o surgimento do Rosa Elze e Rosa Maria, concorrendo de um lado para a segregação socioespacial e de outro para a especulação imobiliária. Segundo Menezes (2011), foi sob a interferência do Estado, de forma autoritária e concentradora, que as políticas urbanas foram sendo desenvolvidas, especialmente pelo Governo Federal, uma vez que o poder econômico dos estados e municípios se via, na ocasião, fragilizado e impotente diante das ações impostas. Nesta perspectiva, a intervenção do Estado na transformação do espaço urbano de São Cristóvão, sem sombra de dúvidas, provocou mudanças na paisagem da cidade, especialmente no que se refere à política habitacional.

\begin{abstract}
Assim sendo, a atual estrutura urbana de São Cristóvão reflete as precárias condições econômicas do município e do estado, evidenciadas na insuficiência de serviços de infraestrutura urbana, na falta de emprego, na rotatividade dos moradores dos conjuntos habitacionais e nas desigualdades entre as diferentes classes sociais (SOUZA, 2005, p. 151).
\end{abstract}

Com o surgimento do bairro Rosa Elze, bem como os aglomerados que apareceram no seu entorno em função da política nacional de habitação, diversas pessoas foram atraídas para essa região, deixando o campo para viver na cidade, aumentando consideravelmente o contingente demográfico e a demanda por infraestrutura urbana. Aliado a esse processo, a urbanista Kátia Pizzol destaca que, de maneira geral, o desenvolvimentismo gerou uma quantidade incalculável de problemas para as cidades, cujo processo trouxe "multidões de migrantes demandando habitação, infraestrutura, serviços e empregos; e, consequentemente,

\footnotetext{
${ }^{3}$ A organização do espaço de São Cristóvão ocorre de forma atípica, relativamente à expansão dos elementos de urbanização, pois não se verifica, como é o habitual, uma expansão do núcleo urbano, mas sim um movimento urbanizador imposto pela presença, em certos casos, de conjuntos habitacionais que se instalaram atraídos pela infraestrutura introduzida com a chegada da UFS (SOUZA, 2005).
} 
estas demandas recaíram sobre o poder local, que, na maioria das vezes, não pode atender a todas no tempo necessário" (PIZZOL, 2006, p. 1).

Foi em atenção às demandas geradas pelo crescimento urbano acelerado que a Prefeitura Municipal de São Cristóvão instalou a subprefeitura do GRE no Conjunto Eduardo Gomes - local escolhido para representação do poder público e da aproximação popular com a sede administrativa. Tratava-se de uma medida compensatória que mais serviu como canal de comunicação entre os munícipes e os gestores públicos do que aproximação, propriamente dita, com a sede administrativa, pois os habitantes dessa região sentem-se à mercê do poder público local, guardando relação positiva com Aracaju, que fornece grande parte dos serviços urbanos.

Atualmente, mesmo com certa precariedade, a infraestrutura do bairro é dotada das redes de esgoto e de saneamento básico, com aproximadamente mil metros de ruas não pavimentadas que, em sua maioria, tem rede de drenagem, o que não significa necessariamente que o esgoto tenha uma destinação adequada. $\mathrm{O}$ abastecimento de água é feito pela Companhia de Saneamento de Sergipe, a DESO, diferentemente da sede do município que possui um serviço próprio de abastecimento, sendo atendida pelo SAAE (Serviço Autônomo de Águas e Esgotos). Para melhor e maior atendimento à população do município e também de parte da capital do estado, foi construída uma barragem na bacia do rio Poxim, com vistas a suprir o abastecimento d'água na região.

Um terminal de integração faz a ligação entre Aracaju e as comunidades adjacentes, beneficiando a região com a sua participação no Sistema Integrado de Transportes, SIT, o que possibilita aos usuários desse sistema se deslocar de um ponto a outro da Grande Aracaju, pagando apenas uma passagem. Todavia, o transporte oferecido na região é considerado deficitário, pois circula somente pelas principais vias de acesso ao aglomerado, sendo o conjunto Brigadeiro Eduardo Gomes o mais beneficiado por esse serviço. Conforme indica (Silva: 2010, p. 42):

[...] a acessibilidade ao sistema de transporte público está relacionada com as distâncias que os usuários caminham quando utilizam o transporte coletivo, desde a origem da viagem até o ponto de embarque e do ponto de desembarque até o destino final. Quanto menos o passageiro caminha, melhor é a acessibilidade ao sistema de transporte público. 
A frota de ônibus demonstra-se insuficiente para o atendimento da população nos horários de pico, o que tem provocado a superlotação nos ônibus coletivos, reclamações por parte dos usuários e o fortalecimento de um novo serviço de transporte remunerado de passageiros - "o táxi lotação". Percebe-se, ainda, a carência de equipamentos públicos de esporte e lazer, pois o bairro conta apenas com uma praça composta de uma quadra esportiva e um pequeno parque para os jovens e crianças se divertirem. Conta também com dois postos de saúde, os quais atendem precariamente os casos ambulatoriais, sendo as situações de urgência/emergência encaminhadas para o HUSE (Hospital de Urgências de Sergipe), antigo hospital Governador João Alves Filho, em Aracaju.

O sistema público municipal de educação, em 2014, contava com 38 escolas, atendendo da creche ao ensino fundamental, além da educação de jovens e adultos distribuída tanto na zona urbana como na rural. A população do município também é assistida por escolas da rede estadual, totalizando 18. Destas, todas ministram o ensino fundamental, ficando o ensino médio atendido por 8 desses estabelecimentos. Encontramos ainda mais de 10 escolas particulares, atendendo da pré-escola ao ensino médio. Ressalta-se que é nesse município que se localiza duas das três instituições públicas de ensino superior do estado: a Universidade Federal de Sergipe (UFS), que agrega o Colégio de Aplicação, oferecendo o ensino do $5^{\circ}$ ao $9^{\circ}$ ano e ensino médio, e o Instituto Federal de Sergipe (IFS), campus de São Cristóvão, com ensino de nível médio e superior.

\section{DISCUSSÕES FINAIS}

Dentre os tantos fenômenos observados no município de São Cristóvão as questões relacionadas ao rural e urbano não poderiam ser olvidadas da discussão geográfica, estimulando e contribuindo para a análise dos fatores que ocasionaram as modificações sócioespaciais nas décadas de 1980, 1990 e 2000.

Para tanto, alguns esforços foram envidados no sentido de coletar dados e informações que permitissem a compreensão da organização espacial rural/urbano, cujas delimitações evidenciaram manipulações estratégicas promovidas pelo poder público local no território, em determinados períodos, a fim de satisfazer suas necessidades e conveniências. O rural e o urbano em São Cristóvão, conforme se evidenciou durante o desenvolvimento da pesquisa 
que originou este texto, passaram por um processo de especulação pelo poder público e pelos agentes produtores do espaço.

Em que pese a existência da Lei $n^{\circ} 16$, de 03 de dezembro de 1984, que definiu quase a totalidade do município como urbano, o espaço físico do núcleo sede não foi expandido na mesma proporção dos aglomerados urbanos com características de rural, pois, não obstante a mudança na denominação do uso do solo, isso não implicou necessariamente o desaparecimento das atividades agrícolas.

A ampliação do espaço físico dos diversos núcleos urbanos sãocristovenses é um fato que indica um movimento ininterrupto do crescimento do município. A paisagem nesses núcleos ampliados exprime, contudo, características nitidamente rurais, embora o conteúdo do supracitado documento definisse todos os espaços como eminentemente urbanos.

Há uma nítida compartimentação do espaço em termos de qualidade ambiental e serviços básicos (abastecimento de água, instalação sanitária, destino do lixo), dos quais só as áreas mais próximas aos núcleos urbanos mostram-se mais servidas, pois se trata de uma “periferia planejada", conforme denomina Souza, (2005).

A pesquisa demonstrou que a aplicação da lei de 1984 em relação ao espaço ampliou o perímetro urbano, envolvendo extensas áreas até então consideradas rurais e que obtiveram previamente o status de áreas urbanas.

As atividades exercidas no espaço não mudam necessariamente de imediato quando a área urbana aumenta porque o rebatimento é decorrente dos investimentos de outras políticas do Estado. Desta forma, o Estado novamente intervém de maneira específica através de políticas públicas que influenciam ou determinam sua produção. Cite-se, como exemplo a política do Banco Nacional de Habitação que, através da extinta COHAB, impôs condições para a construção de conjuntos habitacionais somente em espaços definidos como urbanos.

A instituição de novas políticas públicas direcionadas ao rural, principalmente por parte do Governo Federal, levou o poder público local, por meio da Lei $n^{\circ} 21$, de 18 de dezembro de 2002, a revogar a lei anterior, alterando com isso mais uma vez a delimitação do urbano/rural como forma de garantir recursos à municipalidade. Essa nova lei retrata melhor a realidade e está respaldada nos critérios do IBGE com base nos censos de 1991 e 2000. Assim, a partir da lei de 2002, constata-se uma reorganização espacial que reduz a área urbana em prol da área rural. Porém, as áreas atualmente definidas como áreas de expansão urbana por essa lei ainda apresentam características rurais, com atividades agropecuárias, 
suscitando questionamentos sobre o perímetro definido pela mesma e sobre o próprio processo de delimitação da zona urbana e rural.

Assim, com base nas leis que delimitam o espaço municipal, identificam-se em São Cristóvão três situações: 1) localidades que eram urbanas conforme a Lei de 1984 e hoje continuam urbanas segundo a Lei de 2002; 2) localidades pertencentes ao urbano em 1984 e agora ao rural em 2002; 3) localidades rurais em 1984 e que continuam rurais em 2002.

Apesar das transformações visíveis no espaço, a atual estrutura urbana de São Cristóvão reflete as precárias condições econômicas do município e do estado, evidenciadas na insuficiência de serviços de infraestrutura urbana, na falta de emprego, na rotatividade dos moradores dos conjuntos habitacionais e nas desigualdades entre as diferentes classes sociais.

Ao longo dessas últimas décadas, observa-se que São Cristóvão evoluiu bastante em termos de infraestrutura. Isso vem ocorrendo porque os elementos que caracterizam a urbanização realmente vêm crescendo nas áreas dos setores censitários urbanos com características de rural, o que é um indicador da urbanização do município, apesar que algumas dessas áreas mantêm deficiência de serviços, o que implica, de certa forma, um processo de "urbanização desordenada", conforme se observou no trabalho empírico.

Acredita-se que o processo de urbanização pode contribuir para a melhoria na qualidade de vida da população rural se esta tiver acesso aos equipamentos modernos que dinamizem o processo de produção. Porém, conforme a constatação da pesquisa de campo, entraves como a dificuldade de capital e a falta de crédito são indicadores de uma urbanização que se realiza em um processo excludente.

A urbanização ora assistida pelo município de São Cristóvão não deixa de ser um fenômeno ligado às atuais transformações ocorridas no processo de desenvolvimento econômico do país, com todas as suas implicações sobre o uso e a ocupação do solo, fato de se integrar ao espaço da Grande Aracaju. Tais transformações estão presentes no processo urbano, onde sua intensidade vincula-se estritamente à dinâmica da economia estadual com interesses de financiamento de programas do Governo Federal.

Deste modo, torna-se claro que a explicação para o recrudescimento de problemas como baixa renda, desemprego, condições precárias de moradia, migrações, marginalização, entre outros não se inclui apenas a questões relacionadas ao contexto demográfico ou espacial, visto que tais fenômenos são resultantes de processos políticos, econômicos e sociais altamente complexos. 
Ressalte-se que a modificação espacial imposta pelo poder público em 1984 objetivava favorecer suas ações, relativamente as ligadas à construção de conjuntos habitacionais, loteamentos e infraestrutura básica. Daí ampliar o perímetro urbano, apesar de não ter de fato transformado o espaço ou zona rural e suas atividades inerentes em urbanas, embora se observe aí a expansão de algumas características urbanas, o que levou o IBGE, posteriormente (Censo 1991), a classificar o então espaço tido como urbano pela lei de 1984 em setores urbanos com características de rurais, pois estas se mantiveram inalteradas, não havendo incremento, ao contrário do setor terciário, que se apresenta em movimento crescente.

Com a lei de 2002, modifica-se mais uma vez a delimitação do perímetro urbano e rural, transformando-se o espaço anteriormente urbano em espaço rural.

Este é um processo recente, mas tudo leva a crer que possíveis alterações advirão, haja vista a implementação de algumas políticas voltadas para o rural, como é o caso do PRONAF, embora o germe da urbanização já tenha sido disseminado através da repercussão das políticas habitacionais anteriormente implantadas, as quais despertaram para a necessidade de ampliação de serviços e trouxeram expectativas de/na qualidade de vida.

O Estado tem, inegavelmente, o poder de organizar o espaço. Saliente-se que, para tanto, é necessário haver uma articulação entre as três esferas de poder - federal, estadual e municipal - e o povo, representado por meio de conselhos e associações. Desta forma, indispensável torna-se considerar tais elementos na elaboração de uma nova política urbana e rural.

O espaço em foco, apesar das diferentes formas de organização, apresenta-se com baixo nível de mobilização ou de transformação pelo capital. A diferenciação espacial reflete uma estratificação social, sobretudo no campo, onde há uma minoria privilegiada pelo monopólio do principal meio de produção, a terra. $\mathrm{O}$ vasto contingente é representado pelas populações rurais desprovidas de acesso a uma infraestrutura econômica e com carência de bens e serviços essenciais á sobrevivência, as quais, embora contribuam com seu trabalho para o desenvolvimento capitalista, permanecem à margem de seus benefícios. Conclui-se, então, que o capital, embora valorizado, nem sempre é acessível a todos, pois, para render, utiliza-se da supressão da mão de obra local, usufrui dos recursos e se avoluma cada vez mais. Em síntese, o capital cresce e segrega tanto a população quanto o espaço no qual está inserido. 
Por fim, de outra feita, torna-se relevante observar que o presente estudo descritivo, que apresenta caráter exploratório, investiga e questiona a atual organização espacial do território político-administrativo de São Cristóvão, a partir da atuação do poder público local, não pretende encerrar as discussões acerca da dinâmica espacial evidenciada no território sãocristovense, mas sim contribuir para uma maior reflexão e aprofundamento dos debates sobre o espaço dos municípios e, principalmente, do município em tela, tendo em vista a elaboração e implementação da Lei n. 044/2009, de 21 de setembro de 2009, que dispõe sobre o plano Diretor do município de São Cristóvão e dá outras providencias correlatas.

\section{REFERÊNCIAS}

IBGE. INSTITUTO BRASILEIRO DE GEOGRAFIA E ESTATÍSTICA. Censo Agropecuário, Sergipe, 1980. Disponível :em:<http//www. Ibge. gov.br >.Acesso em: 18 set.2014.

.INSTITUTO BRASILEIRO DE GEOGRAFIA E ESTATÍSTICA. Censo Agropecuário, Sergipe, 1985. Disponível:em:<http//www. Ibge. gov.br >.Acesso em: 18 set.2014.

.INSTITUTO BRASILEIRO DE GEOGRAFIA E ESTATÍSTICA. Censo Agropecuário, Sergipe, 1995/96. Disponível:em:<http//www. Ibge. gov.br >.Acesso em: 18 set.2014.

.INSTITUTO BRASILEIRO DE GEOGRAFIA E ESTATÍSTICA. Censo Demográfico, Sergipe, 1970. Disponível:em:<http//www. Ibge. gov.br >.Acesso em: 20 set.2014.

.INSTITUTO BRASILEIRO DE GEOGRAFIA E ESTATÍSTICA. Censo Demográfico, Sergipe, 1980. Disponível:em:<http//www. Ibge. gov.br >.Acesso em: 28 set.2014.

.INSTITUTO BRASILEIRO DE GEOGRAFIA E ESTATÍSTICA. Censo Demográfico, Sergipe, 1991. Disponível:em:<http//www. Ibge. gov.br >.Acesso em: 18 set.2014.

.INSTITUTO BRASILEIRO DE GEOGRAFIA E ESTATÍSTICA. Censo Demográfico, Sergipe, 2000. Disponível:em:<http//www. Ibge. gov.br >.Acesso em: 28 set.2014.

.INSTITUTO BRASILEIRO DE GEOGRAFIA E ESTATÍSTICA. Censo Demográfico, Sergipe, 2010.

CORREAA, Roberto Lobato. Espaço, um conceito-chave da geografia. In: CASTRO, Iná Elias de; 
GOMES, Paulo César da Costa; CORRÊA, Roberto Lobato. (Org.). Geografia: conceitos e temas. Rio de Janeiro: Bertrand Brasil, 1995. p. 15-47.

CORRÊA, R. L. O espaço urbano. São Paulo: Ática, 1993.

FRANÇA, Vera Lúcia Alves. Aracaju: Estado \& metropolização. São Cristóvão: UFS, 1999.

GUIMARÃES, N. A. Regiões metropolitanas: aspectos jurídicos. Jus Navigandi, Teresina, ano 9, n. 273, 6 abr. 2004. Disponível em: 〈http://jus.uol.com.br/revista/texto/5050〉.

Acesso em: 22 fev. 2014.

LIMA, Justino Alves. Comunidades carentes: lugares da não-informação. Tese (Doutorado em Ciências da Informação). São Paulo: USP, 2006.

MENEZES, C. R. C. Dinâmica Urbana do Bairro Rosa Elze: o papel das políticas públicas na transformação do espaço. Revista Scientia Plena. Vol. 7 n. 11, novembro de 2011

OLIVEIRA, José Aldemir. A cidade no horizonte do provável: políticas e desenvolvimento urbano. In: SILVA, José Borzacchiello; COSTA, Maria Clélia L.; DANTES, E. Wanderley C. (Org.). A cidade e o urbano. Fortaleza, EUFC, 1997

PIZZOL, Kátia Maria S. Andrade. A dinâmica urbana: uma leitura da cidade e da qualidade de vida no urbano. Caminhos da Geografia (UFU. Online), v. 07, p. 01-07, 2006.

PREFEITURA de São Cristóvão. Plano urbanístico de São Cristóvão. v. 1 - Análise do Meio Físico Social, Convênio SEPLAN PR - Governo do estado de Sergipe EMSETUR/UFBA Salvador, 1980.

Lei n. ${ }^{\circ}$ 16, de 03 de dezembro de 1984. Declara Zona Urbana e de Expansão Urbana Área que especifica. Câmara Municipal de São Cristóvão, São Cristóvão, 03 dez. 1984.

Lei n. ${ }^{\circ}$ 21, de 18 de dezembro de 2002. Revoga a Lei n. ${ }^{\circ} 16 / 1984$ e dá outras providências. Câmara Municipal de São Cristóvão, São Cristóvão, 18 dez. 2002.

Lei n. 044 de 21 de setembro de 2009. Dispõe sobre o Plano Diretor do Município de São Cristóvão e dá providencias correlatas.

RODRIGUES, M.Z.M. D. Evolução do uso e ocupação do solo do conjunto brigadeiro Eduardo Gomes. 2005. Monografia (Bacharelado em Geografia), Universidade Federal de Sergipe. São Cristóvão, SE.

SERGIPE. Constituição estadual de Sergipe. Aracaju: Assembleia legislativa, 05 de outubro de 1989. Disponível em http://www2.senado.leg.br/bdsf/bitstream/handle/id/70454/SE-EC1.pdf?sequence=1. Acessado em 2 de janeiro de 2015 .

SILVA, A. H. Determinação da área de captação de uma estação de metro por meio da utilização do modelo prisma espaço-tempo e padrões de viagens, 2010. Dissertação 
(Mestrado em Transportes) Programa de Pós-Graduação em Transportes. Universidade de Brasília.

SOUZA, Fábio Silva. Arqueologia do cotidiano: um flâneur em São Cristóvão/SE, 2004. Dissertação (Mestrado em Geografia), Programa de Pós Graduação em Geografia, Universidade Federal de Sergipe.

SOUZA, Otávio Cezar Juliano. O Rural e o urbano: uma análise espacial do município de São Cristóvão/SE, 2005. Dissertação (Mestrado em Geografia). Programa de Pós Graduação em Geografia, Universidade Federal de Sergipe.

Recebido em Julho de 2015

Aprovado em Março de 2016

Publicado em Junho de 2016 